\title{
БИОЛОГИЧЕСКАЯ ОЦЕНКА ГРЕЧНЕВОЙ МУЧКИ
}

\author{
Т. А. Никифорова, С. А. Леонова, И. А. Хон
}

В статье рассматриваются вопросы, касающиеся разработки научно обоснованных решений для реализации ресурсосберегающих технологий рационального использования вторичного сырья крупяного производства. В качестве основного материала для исследования использовали образцы гречневой мучки, выработанной на Сорочинском комбинате хлебопродуктов (Оренбургская область). Проведено подробное исследование химического состава побочного продукта крупяного производства - гречневой мучки. В ходе работы было отмечено важное преимущество гречневой мучки, выраженное в комплексности её химического состава. В связи с перспективой использования гречневой мучки в пищевых целях была проведена оценка её санитарно-гигиенического состояния. Биологическую оценку гречневой мучки проводили с помощью биологического метода в опытах на животных. Данные, полученные в ходе исследования росто-весовых показателей и азотистого баланса опытных животных, легли в основу оценки биологической ценности белков гречневой мучки. Биологическая оценка белков гречневой мучки, определенная в экспериментах на животных, свидетельствует о высокой биологической эфффективности, усвояемости и утилизации белков гречневой мучки. Проведенные исследования установили перспективность использования гречневой мучки для обогащения продуктов питания растительным белком.

Ключевые слова: биологическая оценка, побочные продукты, крупяное производство, гречневая мучка.

Одними из основных направлений «Стратегии повышения качества пищевой продукции до 2030 г.», принятой согласно распоряжению Правительства Российской Федерации от 29.06.2016 г. №1364-р, являются обеспечение полноценного питания, профрилактика заболеваний, увеличение продолжительности и повышение качества жизни населения [1, 2]. Для этого активно ведётся разработка новых функциональных продуктов питания, способствующих улучшению и сохранению здоровья человека.

Мировой и отечественный опыт свидетельствует, что наиболее результативным и экономически приемлемым способом для обеспечения населения незаменимыми нутриентами является дополнительное обогащение ими продуктов питания массового потребления: муки, хлебобулочных изделий, круп, молока и кисломолочных продуктов [3, 4].

В настоящее время в производстве новых продуктов питания повышенной пищевой ценности всё чаще используют нетрадиционное сырьё. Таким перспективным сырьем могут стать побочные продукты крупяных производств, образующиеся при переработке зерна в крупу.Однако побочные продукты крупяных производств не находят должного практического применения в обогащении продуктов питания и чаще всего используются в качестве компонентов комбикормов.
При переработке зерна гречихи в крупу в качестве побочного продукта образуется мучка. Важным преимуществом гречневой мучки является комплексность её химического состава. Она содержит широкий спектр природных биологически активных компонентов, которые при внесении в продукты питания окажут благотворное воздействие на организм человека $[5,6,7]$.

Комплексное исследование химического состава гречневой мучки показало, что содержание белка в ней составляет 26,8-30,5\%, липидов 6,8-8,7 \%, крахмала 29,7-30,9\%, клетчатки 11,8-15,9 \%. Зольность мучки составляет 7,9-8,9 \%. Проведенные исследования показали, что по содержанию белка мучка превосходит зерно в 2,4 раза, по содержанию липидов - в 3,9 раза, клетчатки - в 2,1 раза $[8,9,10]$, что свидетельствует о её высокой пищевой ценности.

Гречневая мучка содержит полиненасыщенные жирные кислоты: олеиновую $(0,04-$ $0,09 \%)$, линолевую $(0,87-2,1 \%)$ и линоленовую $(30,2-34,17 \%)$. В мучке содержатся такие важные представители стеринов, как $\beta$ ситостерин (1456,0 мкг/г), кампестерин (211,0 мкг/г), обладающие иммуномодулирующими, онкопротекторными, гипогликемическими, антиоксидантными эфрфектами [11].

Исследование показало, что гречневая мучка является источником целого ряда вита- 
минов. Так, содержание витамина В1 составляет 0,40-0,45 мг\%, В2 - 0,31-0,40 мг\%, РP 4,96-6,88 мг\%, витамина Е - 4,12-4,9 мг\%.

Анализ минерального состава гречневой мучки показал, что содержание калия составляет 10800-11210 мг/кг, кальция - 3050-3400 мг/кг, фоосфора - 6500-7800 мг/кг, железа 86-90 мг/кг [6].

Целью исследования являлось проведение комплексной оценки санитарногигиенического состояния и изучение биологической ценности гречневой мучки с помощью биологического метода в опытах на животных. Основными материалами исследования служили образцы мучки, выработанной на Сорочинском комбинате хлебопродуктов (Оренбургская область). Исследования проводились в лабораториях кафедры технологии пищевых производств ФГБОУ ВО «Оренбургский государственный университет», ФГБУН «ФИЦ питания и биотехнологии» (г. Москва), в испытательной лаборатории
ФГБУ государственного центра агрохимической службы «Оренбургский» и испытательном центре ФГБНУ ВНИИ мясного скотоводства.

В связи с перспективой возможности использования гречневой мучки как сырья для обогащения продуктов питания, необходимо провести комплексную оценку ее санитарногигиенического состояния. Для этого исследовали содержание пестицидов, микотоксинов, радионуклидов и токсичных элементов в образцах гречневой мучки.

В качестве образца для исследования использовали мучку, полученную с контрольного рассева (таблица 1).

Полученные результаты исследования показывают, что содержание токсичных элементов и радионуклидов в гречневой мучке значительно ниже предельно допустимой концентрации. Особо отметим, что содержание цезия-137 и стронция-90 в продукте значительно ниже ПДК.

Таблица 1 - Характеристика санитарно-гигиенического состояния гречневой мучки

\begin{tabular}{|c|c|c|}
\hline Показатели & ПДК, мг/кг & Содержание, мг/кг \\
\hline Пестициды: ГХЦГ и изомеры & 0,5 & Не обнаружено \\
\hline ДДТ и его метаболиты & 0,02 & Не обнаружено \\
\hline Этилмеркурхлорид & Не допускается & Не обнаружено \\
\hline 2,4Д-аминная соль & Не допускается & Не обнаружено \\
\hline \multicolumn{3}{|c|}{ Микотоксины: } \\
\hline Афлатоксин В 1 & 0,005 & Не обнаружено \\
\hline Дезоксиниваленол & 0,7 & Не обнаружено \\
\hline Зеараленон & 1,0 & Не обнаружено \\
\hline Т-2 токсин & 0,1 & Не обнаружено \\
\hline \multicolumn{3}{|c|}{ Радионуклиды, Бк/кг: } \\
\hline Цезий-137 & 50 & Менее 13,8 \\
\hline Стронций-90 & 30 & Менее 3,8 \\
\hline \multicolumn{3}{|c|}{ Содержание токсичных элементов: } \\
\hline Свинец & 0,5 & 0,25 \\
\hline Кадмий & 0,1 & 0,017 \\
\hline Ртуть & 0,03 & Не обнаружено \\
\hline Мышьяк & 0,2 & Не обнаружено \\
\hline
\end{tabular}

По результатам эксперимента было установлено, что в гречневой мучке микотоксины и пестициды не содержатся. Проведенная оценка безопасности гречневой мучки показала, что она соответствует действующим требованиям, предъявляемым к безопасности продовольственного сырья.

Таким образом, проведенная оценка основных показателей безопасности гречневой мучки показала, что они соответствуют требованиям СанПиН 2.3.2.1078-01.

Наиболее полное представление о биологической ценности белка гречневой мучки можно получить с помощью биологических методов исследования в опытах над лабораторными животными.

Для участия в эксперименте были взяты две группы крыс-отъемышей. В первой группе (экспериментальной) подопытные получали 
корм, в котором в качестве источника белка была гречневая мучка, во второй (контрольной) - в виде казеина. Продолжительность эксперимента составила 28 суток. Сам эксперимент включал в себя предварительный период, который составил 25 суток, и балансовый - 3 суток. Были определены ростовесовые показатели в период кормления животных (таблица 2).
Результаты исследований ростовесовых показателей опытных животных показали различия в поедаемости корма. У животных, которые получали в качестве источника белка гречневую мучку, скорость роста (суточный привес) была несколько ниже и составила 2,1 г против контрольного 2,4 г. Это в свою очередь обуславливает непропорциональность накопление белка в их организме и прирост массы тела.

Таблица 2 - Росто-весовые показатели опытных животных

\begin{tabular}{|l|c|c|}
\hline \multicolumn{1}{|c|}{ Показатели } & $\begin{array}{c}\text { Экспериментальная } \\
\text { группа }\end{array}$ & Контрольная группа \\
\hline Исходная масса тела, г & $70 \pm 0,5$ & $70 \pm 0,5$ \\
\hline Масса тела в конце опыта, г & $130 \pm 1,1$ & $137 \pm 1,2$ \\
\hline Привес за весь период откорма, г & $60 \pm 1,0$ & $67 \pm 1,1$ \\
\hline Суточный привес, г & $2,1 \pm 0,1$ & $2,4 \pm 0,1$ \\
\hline $\begin{array}{l}\text { Белок, потребленный за весь период экспери- } \\
\text { мента, г }\end{array}$ & $56 \pm 0,5$ & $60 \pm 0,5$ \\
\hline Количество белка, потребленного за сутки, г & $2,0 \pm 0,1$ & $2,2 \pm 0,1$ \\
\hline
\end{tabular}

Для получения объективного представления о перевариваемости и усвояемости белков гречневой мучки необходимо изучить особенности азотистого баланса опытных животных (рисунок 1).

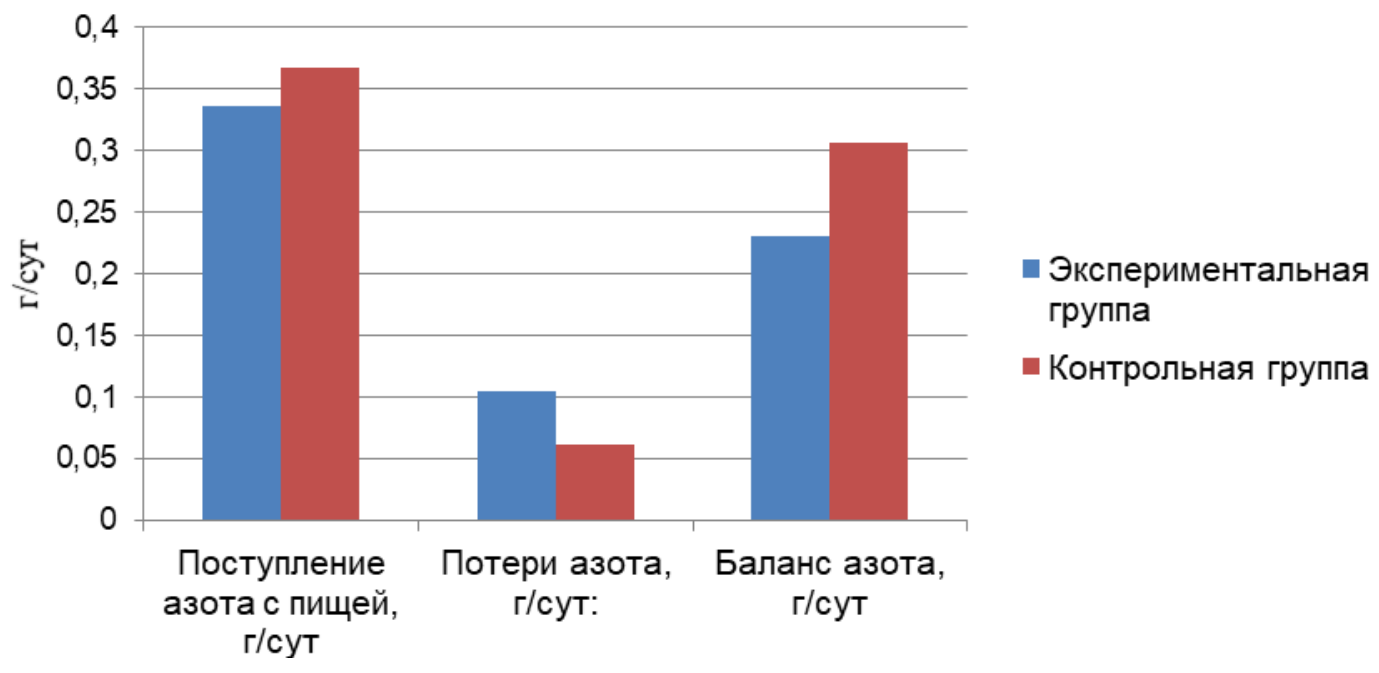

Рисунок 1 - Азотистый баланс опытных животных

На основе полученных данных в обеих группах (экспериментальной и контрольной) опытных животных азотистый баланс имеет положительное значение. Это в свою очередь указывает на процесс роста тканей. Потери азота с экскрементами для группы, в рацион питания которой была включена гречневая мучка, составили 31,25 \%, а для контрольной группы (в рацион питания был включен казеин) $-16,57 \%$.

Данные, полученные в ходе исследования росто-весовых показателей и азотистого баланса опытных животных, легли в основу оценки биологической ценности белков гречневой мучки (рисунок 2). 


\section{БИОЛОГИЧЕСКАЯ ОЦЕНКА ГРЕЧНЕВОЙ МУЧКИ}

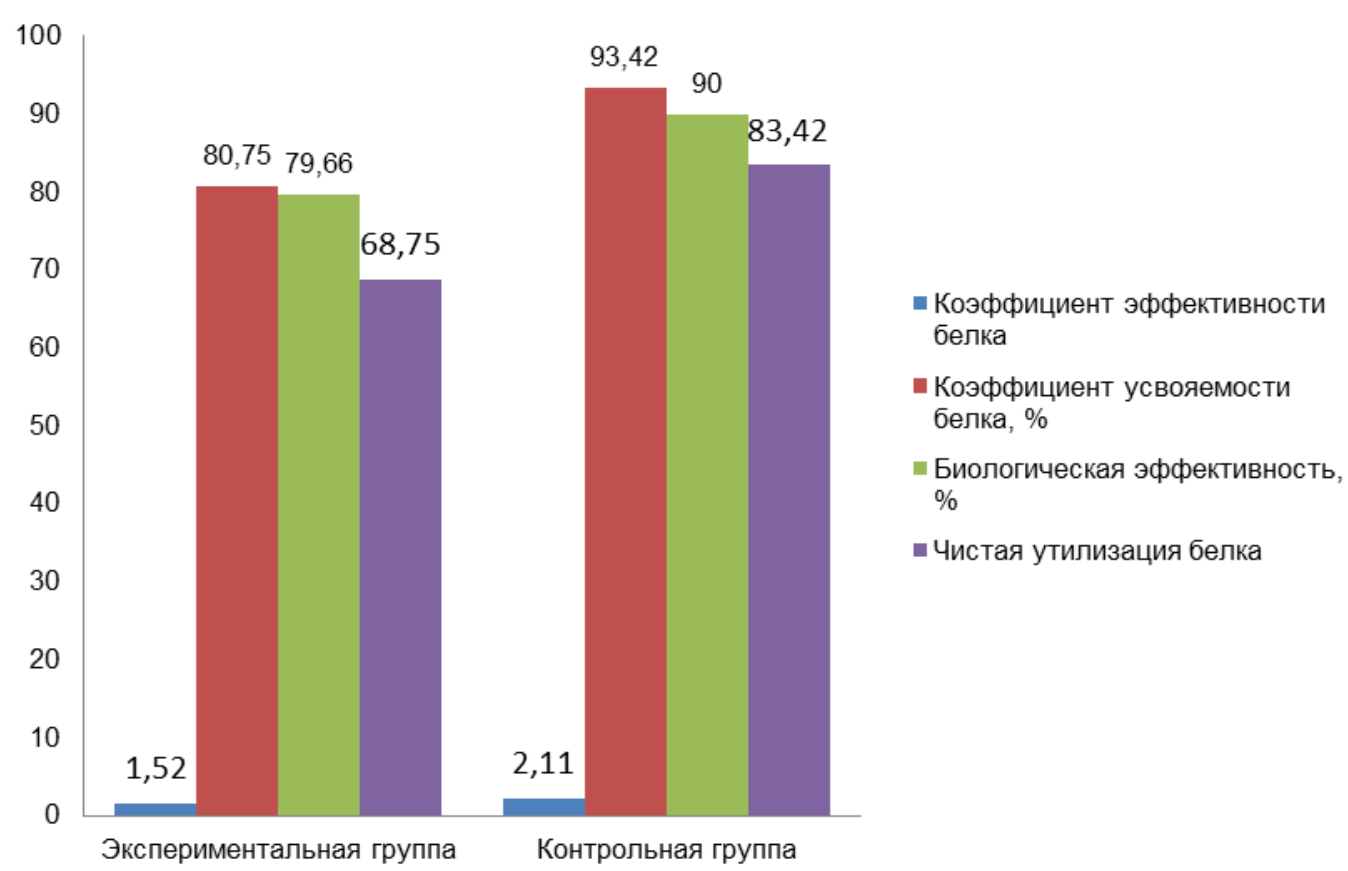

Рисунок 2 - Биологическая оценка гречневой мучки в экспериментах на опытных животных

Значение коэффиициентов эффрективности и усвояемости белка для гречневой мучки чуть ниже контрольных. Как и ожидалось, усвояемость белков гречневой мучки $(80,75$ $\%)$ оказалась ниже, чем у казеина $(93,42 \%)$, и характерна для белков растительного происхождения. Биологическая эфффективность гречневой мучки составила 79,66 \%.

Таким образом, биологическая ценность белков гречневой мучки, определенная в экспериментах на животных, свидетельствуют о высокой биологической эффективности, усвояемости и утилизации белков гречневой мучки. Полученные данные свидетельствуют о перспективности использования гречневой мучки в качестве сырья для обогащения продуктов питания растительным белком.

\section{СПИСОК ЛИТЕРАТУРЫ}

1. Анисимова, Л. В. Реологические свойства теста из смеси пшеничной и цельносмолотой овсяной муки / Л. В. Анисимова, О. И. А. Солтан // Ползуновский вестник. - 2017. - №6. - С. 15-17.

2. Анисимова, Л. В. Товароведческая оценка печенья из смеси пшеничной и просяной муки / Л. В. Анисимова, А. А. Беликова// Вестник алтайской науки. - 2015. - №1 (23). - С.317-322.

3. Иунихина, В. С. Техническое регулирование производства пищевой продукции в ЕАЭС / В. С. Иунихина // Хлебопродукты. - 2017. - №6. - С. 1517.

4. Ильина, О. А. Развитие ассортимента хлеба для здорового питания - актуальная задача от- расли / О. А. Ильнина, В. С. Иунихина // Хлебопродукты. - 2016. - №5. - С. 18-20.

5. Леонова, С. А. Оптимизация дозировки стевиозида в рецептуре коржиков / С. А. Леонова, А. А. Черненкова, Т. А. Никифорова // Технология и товароведение инновационных пищевых продуктов. - 2016. - №6(41). - C. 58-63.

6. Никифорова, Т. А. Перспективы применения побочных продуктов переработки зерна гречихи / Т. А. Никифорова, С. А. Леонова, И. А. Хон // Ползуновский вестник. - 2017. - №1. - С. 8-12.

7. Никифорова, Т. А. Рациональное использование вторичного сырья крупяного производства / Т. А. Никифорова, И. А. Хон, В. Г. Байков // Хлебопродукты. - 2014. - №6. - С. 50-51.

8. Никифорова, Т. А. Физико-химические показатели качества гречневой мучки / Т. А. Никифорова, И. А. Хон // Сборник статей по материалам XLIII Международной научно практической конференции «Технические науки - от теории к практике». Новосибирск, 2015. - С.73-78.

9. Никифорова, Т. А. Использование гречневой мучки в производстве хлеба / Т. А. Никифорова, И. А. Хон // Хлебопродукты. - 2016. - №3. - С. 51-53. 10. Никифорова, Т. А. Влияние гречневой мучки на сохранение свежести хлеба / Т. А. Никифорова, И. А. Хон // Хлебопродукты. - 2017 - №6. - С. 38-40. 11. Никифорова, Т. А. Гречневая мучка - сырьё для производства мучных кондитерских изделий/ Т. А. Никифорова, И. А. Хон // Материалы международной научно-практической конференции «Наука сегодня: глобальные вызовы и механизмы развития», 26 апреля 2017 г. - Вологда, 2017. - С. 22-24.

Никифорова Тамара Алексеевна, доктор техн. наук, профрессор кафедры техно- 
логии пищевых производств, ФГБОУ ВО Оренбургский государственный университет, тел.: (3532) 37-24-67

Леонова Светлана Александровна, доктор техн. наук, доцент кафредры технологии общественного питания и переработки растительного сырья, ФГБОУ ВПО
Башкирский государственный аграрный университет, тел.: (347) 228-07-17

Хон Ирина Александровна, аспирант кафредры технологии пищевых производств, ФГБОУ ВО Оренбураский государственный университет, тел.: (3532) 37-24-67 